Article

\title{
A Biomimetic Strategy for the Fabrication of Micro- and Nanodiamond Composite Films
}

\author{
Kayla Baker (D) and Igor Zhitomirsky *(D) \\ Department of Materials Science and Engineering, McMaster University, Hamilton, ON L8S4L7, Canada; \\ bakerk9@mcmaster.ca \\ * Correspondence: zhitom@mcmaster.ca
}

Citation: Baker, K.; Zhitomirsky, I. A

Biomimetic Strategy for the

Fabrication of Micro- and

Nanodiamond Composite Films.

Micro 2022, 2, 154-163. https://

doi.org/10.3390/micro2010010

Academic Editor: Carlo Santulli

Received: 5 February 2022

Accepted: 21 February 2022

Published: 24 February 2022

Publisher's Note: MDPI stays neutral with regard to jurisdictional claims in published maps and institutional affiliations.

Copyright: (C) 2022 by the authors. Licensee MDPI, Basel, Switzerland. This article is an open access article distributed under the terms and conditions of the Creative Commons Attribution (CC BY) license (https:// creativecommons.org/licenses/by/ $4.0 /)$.

\begin{abstract}
This investigation is motivated by increasing interest in diamond and composite films for applications in biomedical and electronic devices. A biomimetic strategy is based on the use of commercial bile acids, such as ursodeoxycholic acid (UDCA) and hyodeoxycholic acid (HDCA). Composite films are developed using UDCA and HDCA as solubilizing agents for poly(ethyl methacrylate) (PEMA) in isopropanol and as dispersing agents for micro- and nanodiamonds. In this approach, the use of traditional toxic solvents for PEMA dissolution is avoided. The ability to obtain high concentrations of high molecular mass PEMA and disperse diamond particles in such solutions is a key factor for the development of a dip-coating method. The PEMA dissolution and diamond dispersion mechanisms are discussed. The composition and microstructure of the films can be varied by variation of the diamond particle size and concentration in the suspensions. The films can be obtained as singular layers of different compositions, multilayers of similar composition, or alternating layers of different compositions. The films combine corrosion protection property and biocompatibility of PEMA with advanced functional properties of diamonds.
\end{abstract}

Keywords: nanodiamond; microdiamond; poly(ethyl methacrylate); dip coating; film; composite; bile acid; ursodeoxycholic acid; hyodeoxycholic acid

\section{Introduction}

Diamond particles and films have many commercial uses in electronics, tools, and biomedical devices [1-3]. Due to exceptional biocompatibility, hardness, and wear and corrosion resistance, diamond films have many applications for orthopedic implant devices [1,4]. Diamond coatings enhanced corrosion-resistant properties of TiAlV alloys [5]. Additionally, diamond and related materials can stimulate the formation of new bone, leading to enhanced stability and durability of orthopedic implants [6]. Films of diamond were shown to provide thromboresistance, low protein absorption, resistance to fracture, and antibacterial properties for biomedical devices [4,7]. Diamond coatings enhanced biocompatibility, and wear and corrosion resistance of stainless steel [8]. Both micro- and nanodiamond materials [9] were used for coatings of biomedical implants, development of composite scaffolds, and cell culture applications. Recently, significant interest has been generated in biomedical applications of nanodiamond for various biomedical devices [10-14]. Nanodiamond coatings on titanium promoted mammalian cell growth and inhibited Staphylococcus aureus colonization [15]. Cell proliferation was enhanced by the nanodiamond coatings [16]. Novel multifunctional diamond-based materials were developed for advanced biomedical applications [17]. Many investigations focused on the development of advanced techniques for the fabrication of diamond-like carbon coatings on biomedical implants for orthopedic applications [18-20]. Such coatings provided enhanced biocompatibility and prevented inflammation [20].

The development of composite films offers benefits of combining functional properties of diamond with properties of polymers [1] and hydroxyapatite [21]. It has been shown that 
combining various polymers, such as chitosan, polycarbonate, 2-methacryloyloxyethylphosphorylcholine, polytetrafluoroethylene, and silk with diamond allowed for increased mechanical properties, controlled drug release, improved chemical resistance, decreased biofouling, and increased adhesion to substrates [22,23]. Many strategies included spin coating for polymer deposition followed by an additional deposition step for the diamond deposition using different deposition techniques, such as radio frequency plasma-enhanced chemical vapor deposition, plasma immersion ion implantation, and inductively coupled plasma-assisted sputtering [23,24]. Composite films were also obtained by electrophoretic co-deposition from colloidal suspensions, containing particles of diamonds and submicrometre polymer particles [25] using bile acids as negatively charged dispersants in an ethanol solvent. Colloidal techniques offer many benefits for the fabrication of composites with advanced microstructure and functionality [26-30]. The research progress in this area is largely based on the success in the development of efficient surface functionalization techniques $[26,27,30,31]$. However, diamond is one of the most chemically inert materials known [9], and its functionalization and dispersion by adsorbed dispersants present difficulties. Moreover, it is challenging to co-disperse large particles of various commercial polymers and diamond particles for colloidal manufacturing of composites.

The goal of this investigation was the deposition of poly(ethyl methacrylate) (PEMA)diamond composites by a simple dip-coating method. PEMA is an advanced polymer for many applications due to its biocompatibility, high chemical stability, flexibility, good mechanical properties, and thermal stability $[32,33]$. Biomimetic approaches offer many advantages, such that materials assembled in nature often possess superior properties and they were assembled in their native physiological environment-typically ambient temperature and pressures. Therefore, these strategies can help avoid the need for complicated, high-temperature fabrication processes. For example, the mechanism of mussels' strong adhesion to multiple surfaces can be mimicked for the dispersion of metal oxides [34]. This approach was based on the application of natural bile acid biosurfactants, such as ursodeoxycholic acid (UDCA) and hyodeoxycholic acid (HDCA), as solubilizing agents for PEMA and dispersants for diamond particles. Bile acids are physiologically important surfactants that aid in the solubilization of lipids, proteins, cholesterol, vitamins, and other molecules within the human body. In this biomimetic approach, the use of traditional toxic solvents for PEMA dissolution was avoided. The high solubilization and dispersion power of the biosurfactants was linked to their unique chemical structure and properties. The results presented below indicate that composite films containing micro- or nanodiamond can be obtained. The method allows for the variation of film composition. The composite films can be prepared as singular layers or laminates, containing layers of different compositions. The composite coatings offer advantages of combining functional properties of PEMA and diamond.

\section{Materials and Methods}

\subsection{Fabrication of PEMA Solutions and Diamond Suspensions}

PEMA (515 kDa), UDCA, HDCA, microdiamond (MD, $\leq 1 \mu \mathrm{m}$ ), and nanodiamond $(\mathrm{ND},<10 \mathrm{~nm})$ were purchased from Millipore Sigma. PEMA was added at a concentration of $10 \mathrm{~g} \mathrm{~L}^{-1}$ to pure isopropanol as well as isopropanol containing dissolved $1 \mathrm{~g} \mathrm{~L}^{-1}$ of either UDCA or HDCA. The PEMA suspensions were stirred while being heated to $45^{\circ} \mathrm{C}$. At this temperature, the PEMA suspension changed from opaque white to a transparent solution. In the absence of UDCA and HDCA, PEMA was not solubilized and remained opaque white upon cooling. The UDCA and HDCA containing PEMA solutions were stable and clear at room temperature for over $24 \mathrm{~h}$. Such solutions were used for the fabrication of PEMA films. MD and ND were added to the PEMA solutions and ultrasonicated in order to achieve stable diamond dispersions in PEMA solutions. In the addition of $1 \mathrm{~g} \mathrm{~L}^{-1}$ of MD or ND, $1 \mathrm{~g} \mathrm{~L}^{-1}$ of HDCA or UDCA was able to successfully disperse the particles. Whereas, when MD and ND concentrations were increased to $3 \mathrm{~g} \mathrm{~L}^{-1}$, the concentration of UDCA or HDCA was increased to $3 \mathrm{~g} \mathrm{~L}^{-1}$. 


\subsection{Film Deposition}

PEMA films were fabricated by the dip-coating method on 304 stainless steel substrates from $10 \mathrm{~g} \mathrm{~L}^{-1}$ PEMA solutions. Substrates were cut to $2.5 \mathrm{~cm} \times 5 \mathrm{~cm}$ and washed with ethanol before film deposition. PEMA and PEMA-diamond films were deposited by manually lowering the substrate into solution for $20 \mathrm{~s}$, followed by gradual removal, and left to dry in air. The films were deposited as singular PEMA layers, PEMA-diamond composite layers (with different diamond concentrations), PEMA multilayers, and alternating layers of PEMA and PEMA-diamond composites.

\subsection{Film Characterization}

The films were observed on a JEOL (Japan)7000F scanning electron microscope (SEM). A PARSTAT 2273 potentiostat (Princeton Applied Research, USA) was used for potentiodynamic polarization tests of the annealed PEMA films in 3\% $\mathrm{NaCl}$ electrolyte with a saturated calomel reference electrode (SCE) and a Pt counter electrode. A Bruker (USA) Smart 6000 diffractometer ( $\mathrm{CuK} \alpha$ radiation) was used for $\mathrm{X}$-ray diffraction studies.

\section{Results and Discussion}

Figure 1 shows chemical structures of PEMA, UDCA, and HDCA. PEMA is a hydrophobic acrylate polymer, which is soluble only in relatively toxic and carcinogenic solvents, such as methyl ethyl ketone, toluene, and benzene. The hydrophobicity of PEMA is attributed to its hydrocarbon groups. Isopropanol is known as a non-solvent for PEMA. The solubility of PEMA in non-toxic solvents is important for biomedical applications of this polymer and its composites. UDCA and HDCA belong to the bile acid family of organic molecules. It is known that bile acids and bile acid salts are very powerful natural solubilizing and dispersing agents, which outperform various commercial surfactants [35-37].
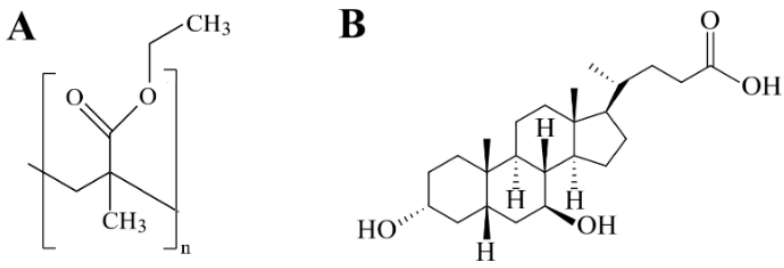

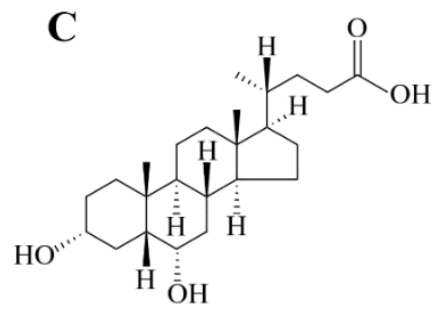

Figure 1. Chemical structures of (A) PEMA, (B) UDCA, and (C) HDCA.

UDCA and HDCA are steroid amphiphilic molecules, which have a hydrophobic hydrocarbon convex face and a concave hydrophilic face with a carboxylic and OH groups [36]. The adsorption of bile salts on different hydrophobic surfaces is influenced by hydrophobic interactions of their convex face with hydrophobic surfaces of materials [36]. The electric charge of bile acids and salts is related to their carboxylic groups, which facilitate electrostatic dispersion. Motivated by strong solubilization and dispersion power of bile acids and salts, we developed a biomimetic strategy that involved solubilization of PEMA in isopropanol and dispersion of diamonds using UDCA and HDCA as solubilizing and dispersing agents, illustrated in Schematic 1 in Supplementary Information. 
We demonstrated for the first time that UDCA and HDCA can solubilize PEMA in isopropanol. Figure 2A demonstrates solubilization of PEMA in the presence of UDCA and HDCA.

A

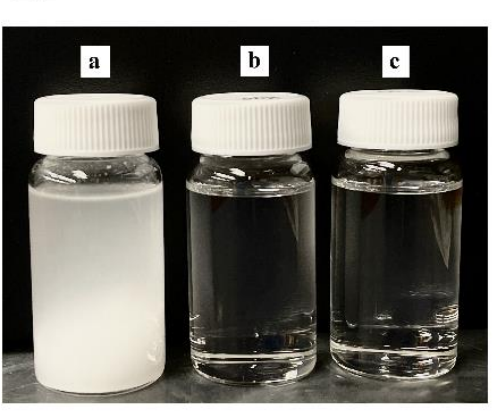

B

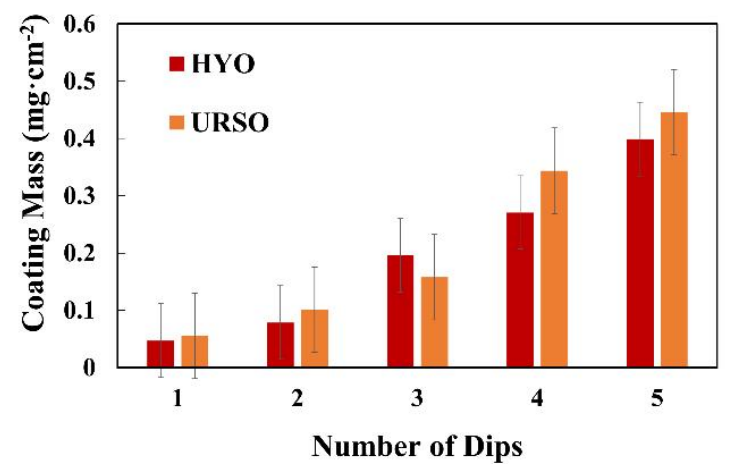

Figure 2. (A) $10 \mathrm{~g} \mathrm{~L}^{-1}$ PEMA in isopropanol: (a) without additives, (b) with $1 \mathrm{~g} \mathrm{~L}^{-1} \mathrm{HDCA}$, and (c) with $1 \mathrm{~g} \mathrm{~L}^{-1}$ UDCA at room temperature, (B) deposit mass versus number of dips from $10 \mathrm{~g} \mathrm{~L}^{-1}$ PEMA with $1 \mathrm{~g} \mathrm{~L}^{-1} \mathrm{HDCA}$ or UDCA.

It is suggested that hydrophobic interactions of PEMA with bile acids facilitated bile acid adsorption on PEMA, resulting in solubilization. It is, in this regard, that bile acid salts solubilize different hydrophobic molecules, such as cholesterol, lipids, and other molecules and macromolecules in a human body. Of particular importance is the ability to form concentrated solutions of high molecular mass PEMA, which was a key factor for the dip-coating deposition of PEMA and composites. Low molecular mass polymers exhibit poor film-forming and binding properties. However, the solubility of polymers usually decreases with increasing their molecular mass. Relatively high polymer concentrations are necessary for film formation by dip-coating. The solubilization of polymer molecules in solvents usually involves polymer chain disentanglement [38], which can be enhanced in the presence of adsorbed anionic UDCA and HDCA molecules. It is hypothesized that heating the PEMA suspensions in isopropanol facilitated penetration of small HDCA and UDCA between the PEMA chains and facilitated dissolution.

In this investigation, the use of traditional toxic solvents for PEMA solubilization was avoided, and PEMA films were successfully deposited on stainless steel substrates from concentrated high molecular mass PEMA solutions in isopropanol. Figure $2 \mathrm{~B}$ shows that PEMA films can be deposited as multilayers. Each dip-coat procedure results in the formation of one layer. Thus, by repeating the number of dips, the number of layers increases. Therefore, it is shown that the film mass can be increased with the increasing number of the deposited layers. Film mass was averaged over six different samples of the same size. Previous investigations [25] of electrophoretic deposition of materials using bile acids as dispersants showed that deposition yield is influenced by the positions of $\mathrm{OH}$ groups in their chemical structure. However, similar deposition yields were obtained by the dip-coating method using HDCA and UDCA with different $\mathrm{OH}$ group positions in their structure. As-deposited films were porous (Figure 3), their annealing at $180{ }^{\circ} \mathrm{C}$ for $1 \mathrm{~h}$ resulted in the formation of dense films. The changes in film morphology after annealing has been attributed to increased polymer mobility at elevated temperatures above the polymer's glass transition temperature [39]. This results in the elimination of pores and the formation of a featureless, dense film. 

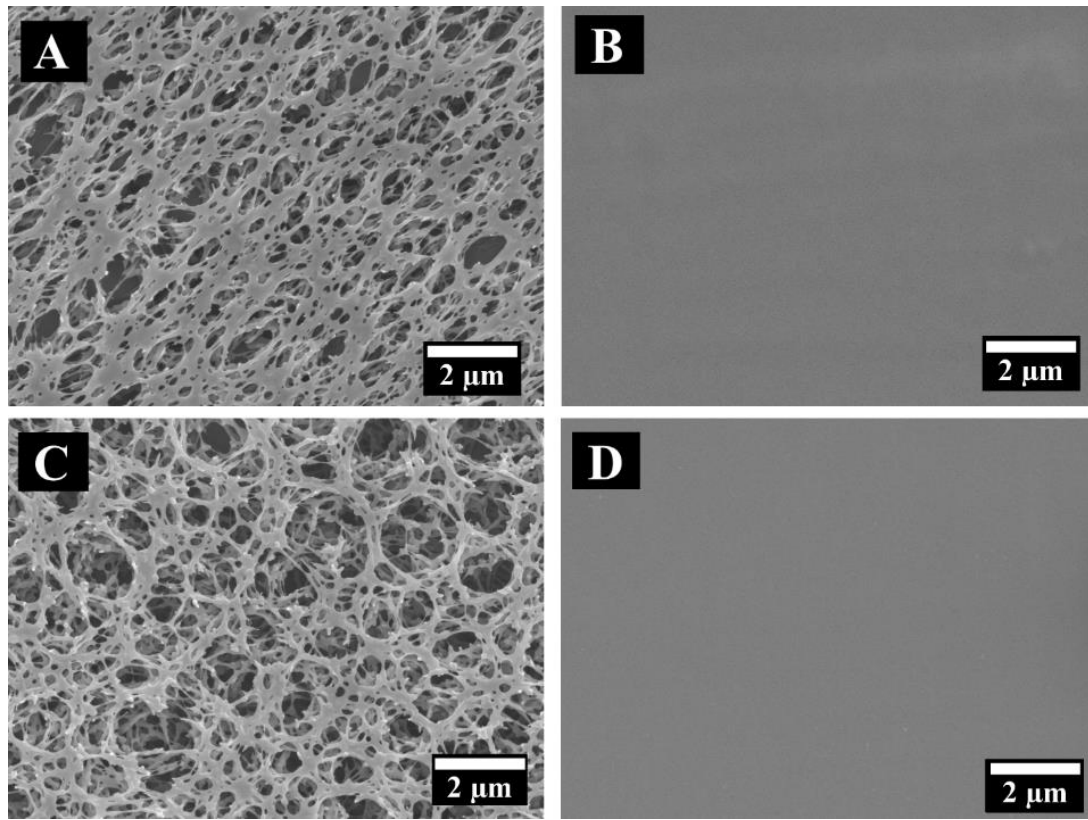

Figure 3. SEM micrographs of films, prepared from $10 \mathrm{~g} \mathrm{~L}^{-1}$ PEMA solutions in isopropanol containing (A,B) $1 \mathrm{~g} \mathrm{~L}^{-1}$ UDCA and (C,D) $1 \mathrm{~g} \mathrm{~L}^{-1}$ HDCA: (A,C) as-deposited and (B,D) annealed at $180^{\circ}$ for $1 \mathrm{~h}$.

Annealed PEMA films provided corrosion protection of stainless steel substrates (Figure 4). The corrosion current of the bare substrate of $3.24 \mu \mathrm{A} \mathrm{cm}{ }^{-2}$ was decreased to $0.34 \mu \mathrm{A} \mathrm{cm}{ }^{-2}$ and $0.72 \mu \mathrm{A} \mathrm{cm}{ }^{-2}$ for the films obtained from $1 \mathrm{~g} \mathrm{~L}^{-1}$ HDCA and UDCAcontaining PEMA solutions, respectively. The Tafel plots also show the increase in the corrosion potential of the coated substrates. The corrosion current obtained by annealed PEMA films which were solubilized in ethanol by lithocholic acid, from our previous work [39], was $0.15 \mu \mathrm{A} \mathrm{cm}^{-2}$. We believe the corrosion current presented here is slightly higher due to small differences in thicknesses of the films between the two works.

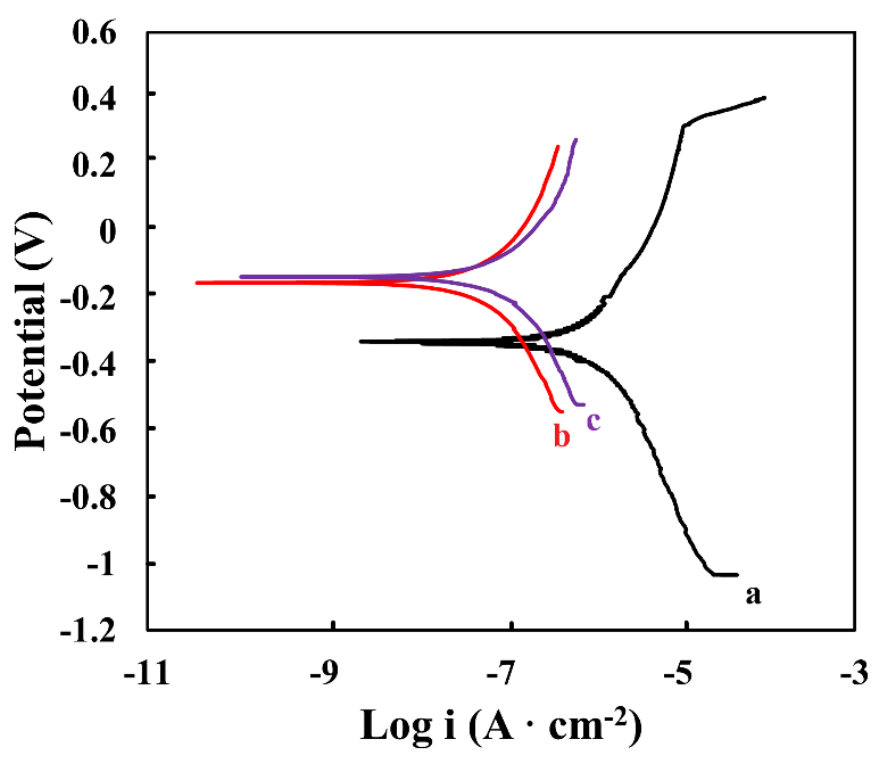

Figure 4. Tafel plots of (a) bare stainless steel substrate, $(\mathrm{b}, \mathrm{c})$ coated with PEMA using (b) $1 \mathrm{~g} \mathrm{~L}^{-1}$ HDCA and (c) $1 \mathrm{~g} \mathrm{~L}^{-1}$ UDCA. 
HDCA and UDCA were also used as dispersants for the dispersion of ND or MD in isopropanol. Figure 5 shows sedimentation tests, which indicated that HDCA and UDCA can be used as dispersing agents for ND and MD.

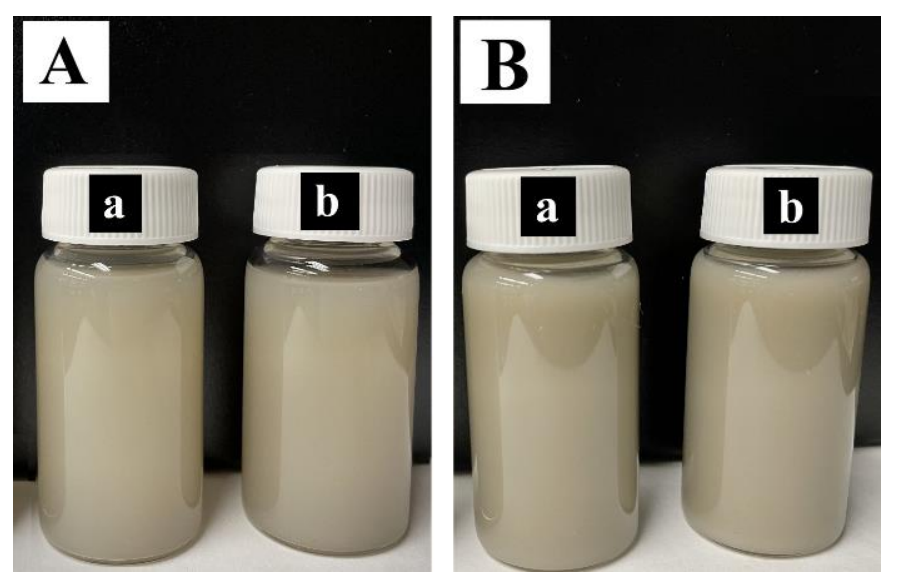

Figure 5. Diamond suspensions obtained using (A) HDCA and (B) UDCA, containing either (a) ND, or (b) MD.

It is hypothesized that adsorption of anionic HDCA and UDCA molecules on diamond surfaces allowed for electrostatic dispersion of the diamond particles. As pointed out above, diamond is one of the most chemically inert materials known [9]. Therefore, it is challenging to achieve diamond dispersion by adsorbed dispersants. This problem was successfully addressed using HDCA and UDCA molecules as dispersants.

Composite PEMA-diamond films were obtained using HDCA and UDCA as solubilizing agents for PEMA and dispersing agents for diamonds. The incorporation of diamonds in the composite films was confirmed by XRD and SEM. Figure 6 shows XRD patterns of the composite films. The XRD patterns showed diamond peaks corresponding to JCPDS file 6-675. Figure 7 presents SEM images of films prepared from $10 \mathrm{~g} \mathrm{~L}^{-1}$ PEMA solutions, containing $1 \mathrm{~g} \mathrm{~L}^{-1} \mathrm{MD}$ or ND, prepared using HDCA or UDCA. The corresponding images at a low magnification are presented in Supplementary Information, Figure S1. The SEM images indicated that diamond particles were co-deposited with PEMA. In contrast to as-deposited PEMA films (Figure 3C,D), which were porous, the incorporation of diamonds resulted in the formation of dense films (Figures 7 and S1). This change in morphology suggested interactions between the PEMA molecules and diamond particles in suspension. The amount of MD and ND in the films can be varied. Figures 8 and S2 show SEM images at different magnifications for the films prepared from $10 \mathrm{~g} \mathrm{~L}^{-1}$ PEMA solutions, containing $3 \mathrm{~g} \mathrm{~L}^{-1} \mathrm{MD}$ or ND, using HDCA and UDCA. The increase in the MD and ND concentration in solutions resulted in the larger diamond content in the films. 


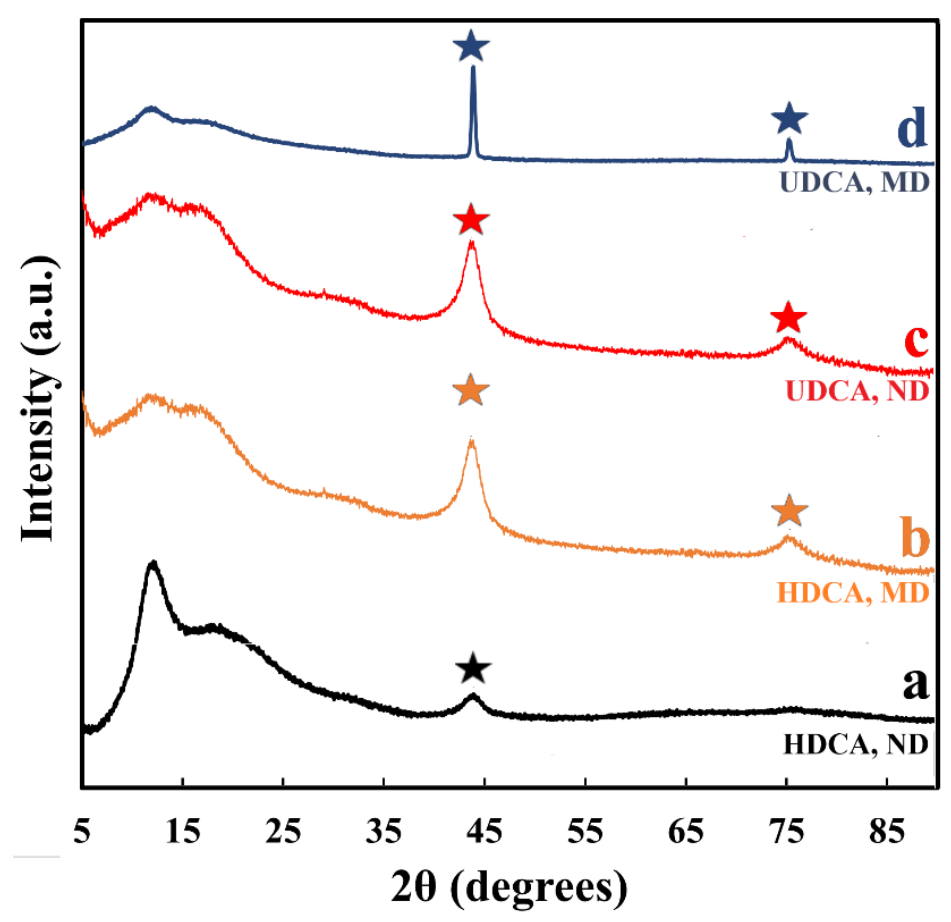

Figure 6. X-ray diffraction patterns of composite films, prepared from $10 \mathrm{~g} \mathrm{~L}^{-1}$ PEMA solutions, containing (a) $3 \mathrm{~g} \mathrm{~L}^{-1} \mathrm{HDCA}$ with $3 \mathrm{~g} \mathrm{~L}^{-1} \mathrm{ND}$, (b) $3 \mathrm{~g} \mathrm{~L}^{-1} \mathrm{HDCA}$ with $3 \mathrm{~g} \mathrm{~L}^{-1} \mathrm{MD}$, (c) $3 \mathrm{~g} \mathrm{~L}^{-1}$ UDCA with $3 \mathrm{~g} \mathrm{~L}^{-1} \mathrm{ND}$, and (d) $3 \mathrm{~g} \mathrm{~L}^{-1} \mathrm{UDCA}$ with $3 \mathrm{~g} \mathrm{~L}^{-1} \mathrm{MD}$ ( $\star$ - peaks of diamond).
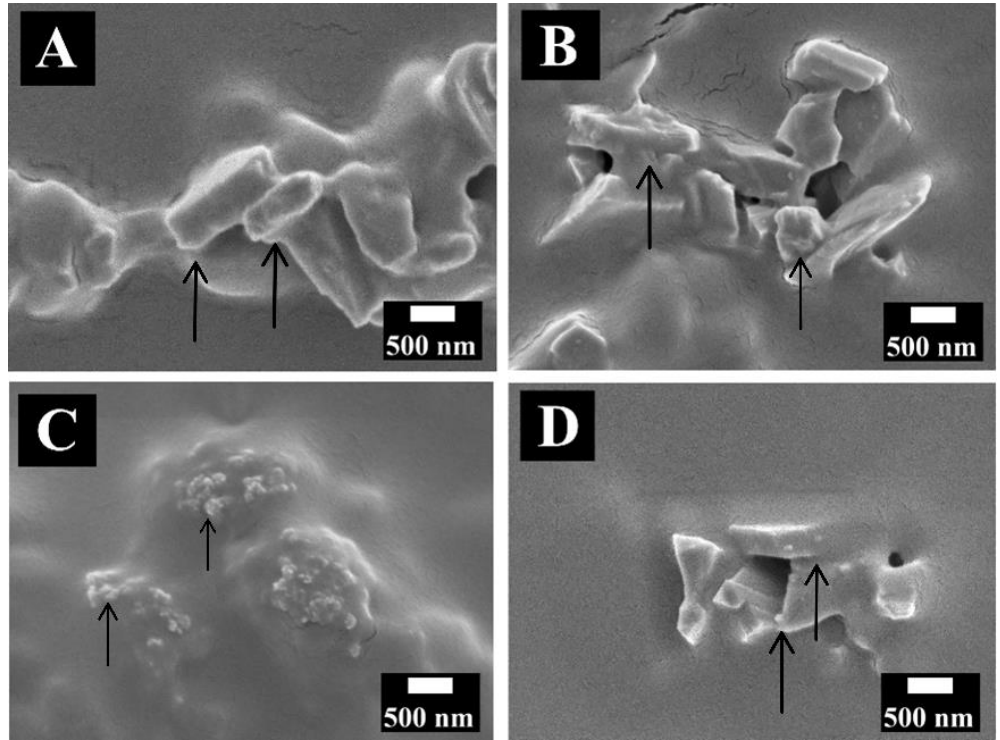

Figure 7. SEM micrographs of films prepared from $10 \mathrm{~g} \mathrm{~L}^{-1}$ PEMA solutions containing (A) $3 \mathrm{~g} \mathrm{~L}^{-1}$ UDCA with $1 \mathrm{~g} \mathrm{~L}^{-1} \mathrm{MD}$, (B) $3 \mathrm{~g} \mathrm{~L}^{-1}$ HDCA with $1 \mathrm{~g} \mathrm{~L}^{-1} \mathrm{MD}$, (C) $3 \mathrm{~g} \mathrm{~L}^{-1}$ UDCA with $1 \mathrm{~g} \mathrm{~L}^{-1} \mathrm{ND}$, and (D) $3 \mathrm{~g} \mathrm{~L}^{-1} \mathrm{HDCA}$ with $1 \mathrm{~g} \mathrm{~L}^{-1} \mathrm{ND}$. Two example arrows per image are added to indicate locations of diamond particles within the film. 

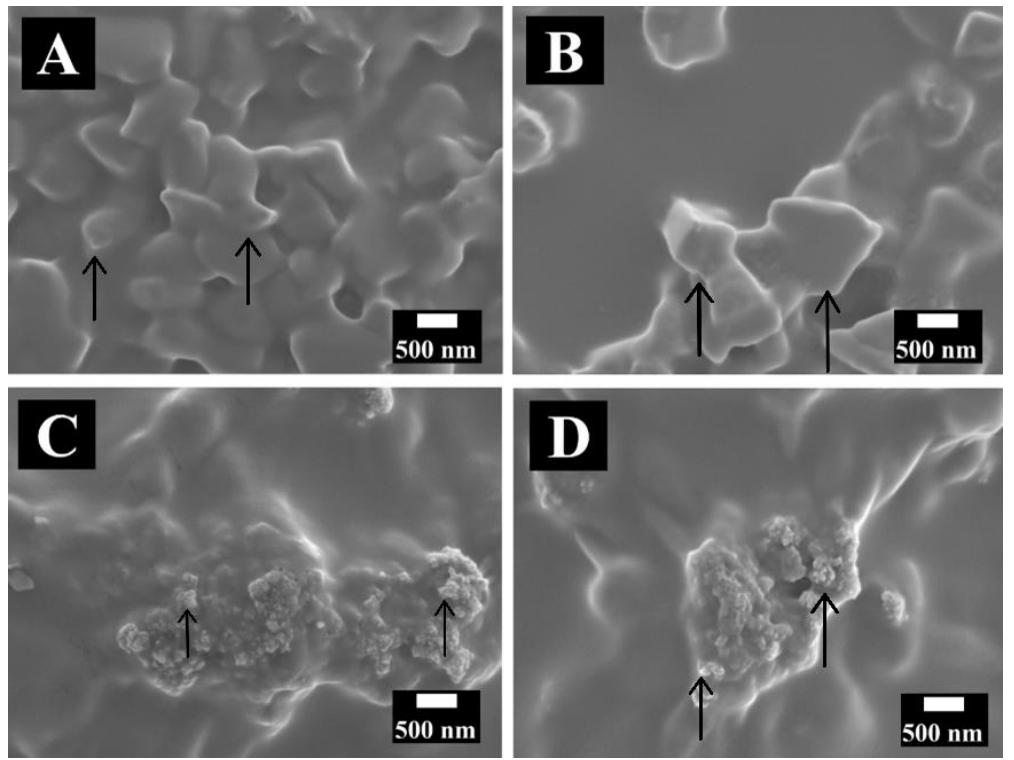

Figure 8. SEM micrographs of films prepared from $10 \mathrm{~g} \mathrm{~L}^{-1}$ PEMA solutions containing (A) $3 \mathrm{~g} \mathrm{~L}^{-1}$ UDCA with $3 \mathrm{~g} \mathrm{~L}^{-1} \mathrm{MD}$, (B) $3 \mathrm{~g} \mathrm{~L}^{-1}$ HDCA with $3 \mathrm{~g} \mathrm{~L}^{-1} \mathrm{MD}$, (C) $3 \mathrm{~g} \mathrm{~L}^{-1}$ UDCA with $3 \mathrm{~g} \mathrm{~L}^{-1} \mathrm{ND}$, and (D) $3 \mathrm{~g} \mathrm{~L}^{-1}$ HDCA with $3 \mathrm{~g} \mathrm{~L}^{-1} \mathrm{ND}$. Two example arrows per image are added to indicate locations of diamond particles within the film.

The dip-coating method represents a versatile strategy for the deposition of films with different microstructures. The composite films can also be deposited as laminates, containing layers of different compositions. Figure 9 shows that the sequential deposition from pure PEMA solutions and PEMA solutions containing diamonds resulted in the growth of the total film mass, confirming the deposition of alternating layers of different compositions.

A

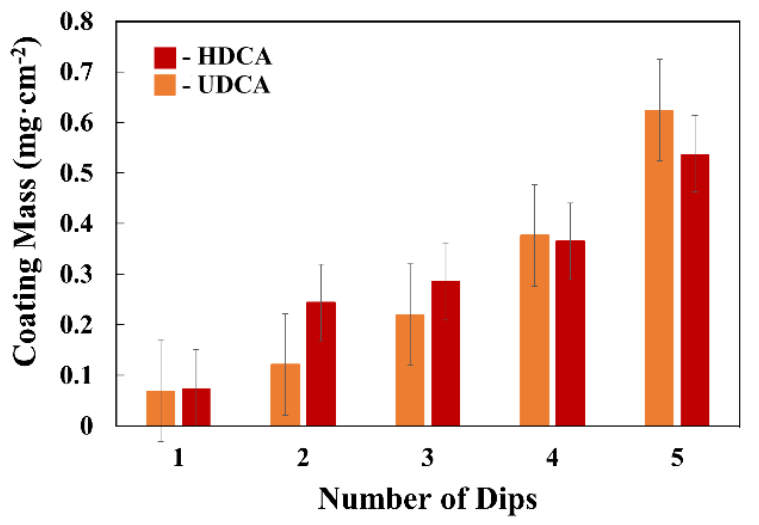

B

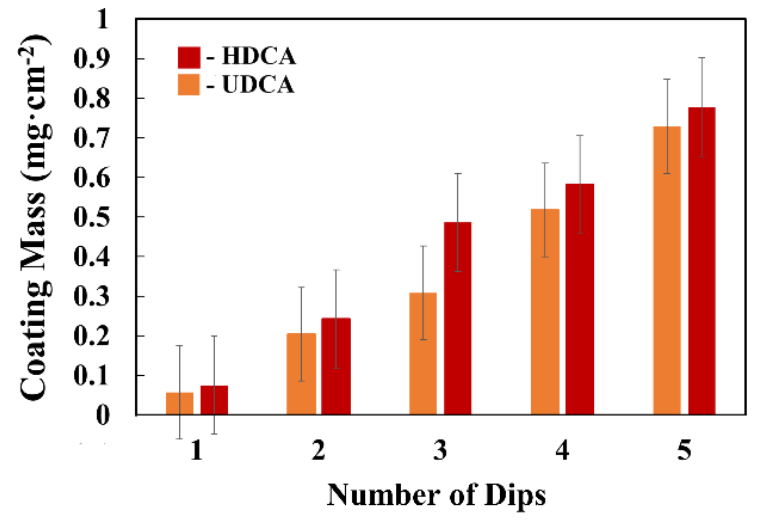

Figure 9. Deposit mass versus number of dips of alternating layers of PEMA and PEMA-diamond using HDCA or UDCA. Layers 1, 3, and 5 were deposited from $10 \mathrm{~g} \mathrm{~L}^{-1}$ PEMA solutions, layers 2 and 4 were deposited from $10 \mathrm{~g} \mathrm{~L}^{-1}$ PEMA solutions, containing (A) $3 \mathrm{~g} \mathrm{~L}^{-1} \mathrm{MD}$ and (B) $3 \mathrm{~g} \mathrm{~L}^{-1} \mathrm{ND}$.

\section{Conclusions}

A biomimetic strategy has been developed for deposition of PEMA-ND and PEMAMD films using HDCA and UDCA bile acids as solubilizing agents for PEMA and dispersing agents for ND and MD. PEMA was successfully dissolved in isopropanol, which is known as a non-solvent for PEMA. The use of traditional toxic solvents can be avoided. The solubilization properties of HDCA and UDCA allowed the fabrication of concentrated high molecular mass PEMA solutions, which played a crucial role in the application of 
a dip-coating technique for pure polymer and polymer-diamond films. The composite films can combine corrosion protection and other functional properties of PEMA with functional properties of MD and ND. The diamond content in the films can be varied. The films can be deposited as single layers or multilayers, containing alternating layers of different compositions.

Supplementary Materials: The following supporting information can be downloaded at: https: / / www.mdpi.com/article/10.3390/micro2010010/s1, Figures S1 and S2: SEM images of PEMAdiamond films at low magnification.

Author Contributions: Conceptualization, K.B. and I.Z.; methodology, K.B.; software, K.B.; validation, K.B. and I.Z.; formal analysis, K.B.; investigation, K.B.; resources, I.Z.; data curation, K.B.; writing—original draft preparation, K.B. and I.Z.; writing—review and editing, K.B. and I.Z.; visualization, K.B.; supervision, I.Z.; project administration, I.Z.; funding acquisition, I.Z. All authors have read and agreed to the published version of the manuscript.

Funding: This research was funded by the Natural Sciences and Engineering Research Council of Canada, grant number RGPIN-2018-04014 and CRC program.

Data Availability Statement: The data presented in this study are available in this manuscript: "A biomimetic strategy for the fabrication of micro- and nanodiamond composite films", as well as in Supplementary Information.

Acknowledgments: The authors acknowledge the support of the Natural Sciences and Engineering Research Council (NSERC) of Canada, CRC program and the Canadian Centre for Electron Microscopy.

Conflicts of Interest: The authors declare no conflict of interest.

\section{References}

1. Wang, Y.; Chen, Q.; Cho, J.; Boccaccini, A. Electrophoretic co-deposition of diamond/borosilicate glass composite coatings. Surf. Coat. Technol. 2007, 201, 7645-7651. [CrossRef]

2. Mani, N.; Ahnood, A.; Peng, D.; Tong, W.; Booth, M.; Jones, A.; Murdoch, B.; Tran, N.; Houshyar, S.; Fox, K. Single-Step Fabrication Method toward 3D Printing Composite Diamond-Titanium Interfaces for Neural Applications. ACS Appl. Mater. Interfaces 2021, 13, 31474-31484. [CrossRef] [PubMed]

3. Yang, K.-H.; Narayan, R.J. Biocompatibility and functionalization of diamond for neural applications. Curr. Opin. Biomed. Eng. 2019, 10, 60-68. [CrossRef]

4. Pandey, P.C.; Shukla, S.; Pandey, G.; Narayan, R.J. Nanostructured diamond for biomedical applications. Nanotechnology 2021, 32, 132001. [CrossRef]

5. Branzoi, I.V.; Iordoc, M.; Branzoi, F.; Rimbu, G.; Marinescu, V. Synthesis and characterization of high-voltage electrodeposited diamond-like carbon protective coating on TiAlV biomedical substrates. Surf. Interface Anal. 2012, 44, 1193-1197. [CrossRef]

6. Starikov, V.; Starikova, S.; Mamalis, A.; Lavrynenko, S. Diamond biocompatible coatings for medical implants. J. Biol. Phys. Chem. 2016, 16, 70-74. [CrossRef]

7. Wang, T.; Huang, L.; Liu, Y.; Li, X.; Liu, C.; Handschuh-Wang, S.; Xu, Y.; Zhao, Y.; Tang, Y. Robust biomimetic hierarchical diamond architecture with a self-cleaning, antibacterial, and antibiofouling surface. ACS Appl. Mater. Interfaces 2020, 12, $24432-24441$. [CrossRef]

8. Li, Y.; Ye, F.; Corona, J.; Taheri, M.; Zhang, C.; Sanchez-Pasten, M.; Yang, Q. CVD deposition of nanocrystalline diamond coatings on implant alloy materials with CrN/Al interlayer. Surf. Coat. Technol. 2018, 353, 364-369. [CrossRef]

9. Nistor, P.; May, P. Diamond thin films: Giving biomedical applications a new shine. J. R. Soc. Interface 2017, $14,20170382$. [CrossRef]

10. Tasat, D.R.; Bruno, M.E.; Domingo, M.; Gurman, P.; Auciello, O.; Paparella, M.L.; Evelson, P.; Guglielmotti, M.B.; Olmedo, D.G. Biokinetics and tissue response to ultrananocrystalline diamond nanoparticles employed as coating for biomedical devices. J. Biomed. Mater. Res. Part B Appl. Biomater. 2017, 105, 2408-2415. [CrossRef]

11. Tien, H.-W.; Lee, C.-Y.; Lin, I.-N.; Chen, Y.-C. Long term in vivo functional stability and encapsulation reliability of using ultra-nanocrystalline diamond as an insulating coating layer for implantable microchips. J. Mater. Chem. B 2017, 5, 3706-3717. [CrossRef] [PubMed]

12. Tinwala, H.; Wairkar, S. Production, surface modification and biomedical applications of nanodiamonds: A sparkling tool for theranostics. Mater. Sci. Eng. C 2019, 97, 913-931. [CrossRef] [PubMed]

13. Turcheniuk, K.; Mochalin, V.N. Biomedical applications of nanodiamond. Nanotechnology 2017, 28, 252001. [CrossRef] [PubMed]

14. Yang, K.-H.; Nguyen, A.K.; Goering, P.L.; Sumant, A.V.; Narayan, R.J. Ultrananocrystalline diamond-coated nanoporous membranes support SK-N-SH neuroblastoma endothelial cell attachment. Interface Focus 2018, 8, 20170063. [CrossRef] 
15. Rifai, A.; Tran, N.; Reineck, P.; Elbourne, A.; Mayes, E.; Sarker, A.; Dekiwadia, C.; Ivanova, E.P.; Crawford, R.J.; Ohshima, T. Engineering the interface: Nanodiamond coating on 3D-printed titanium promotes mammalian cell growth and inhibits Staphylococcus aureus colonization. ACS Appl. Mater. Interfaces 2019, 11, 24588-24597. [CrossRef]

16. Stigler, R.G.; Becker, K.; Bruschi, M.; Steinmüller-Nethl, D.; Gassner, R. Impact of nano-crystalline diamond enhanced hydrophilicity on cell proliferation on machined and SLA titanium surfaces: An in-vivo study in rodents. Nanomaterials 2018, 8, 524. [CrossRef]

17. Perevedentseva, E.; Karmenyan, A.; Lin, Y.-C.; Song, C.-Y.; Lin, Z.-R.; Ahmed, A.-I.; Chang, C.-C.; Norina, S.B.; Bessalova, V.; Perov, N. Multifunctional biomedical applications of magnetic nanodiamond. J. Biomed. Opt. 2018, 23, 091404.

18. Choudhury, D.; Morita, T.; Sawae, Y.; Lackner, J.M.; Towler, M.; Krupka, I. A novel functional layered diamond like carbon coating for orthopedics applications. Diam. Relat. Mater. 2016, 61, 56-69. [CrossRef]

19. Ding, H.; Fridrici, V.; Geringer, J.; Fontaine, J.; Kapsa, P. Influence of diamond-like carbon coatings and roughness on fretting behaviors of Ti-6Al-4V for neck adapter-femoral stem contact. Wear 2018, 406, 53-67. [CrossRef]

20. Liao, T.; Zhang, T.; Li, S.; Deng, Q.; Wu, B.; Zhang, Y.; Zhou, Y.; Guo, Y.; Leng, Y.; Huang, N. Biological responses of diamond-like carbon (DLC) films with different structures in biomedical application. Mater. Sci. Eng. C 2016, 69, 751-759. [CrossRef]

21. Strąkowska, P.; Beutner, R.; Gnyba, M.; Zielinski, A.; Scharnweber, D. Electrochemically assisted deposition of hydroxyapatite on Ti6Al4V substrates covered by CVD diamond films-Coating characterization and first cell biological results. Mater. Sci. Eng. C 2016, 59, 624-635. [CrossRef] [PubMed]

22. Eshaghi, A.; Salehi, M. Fabrication and characterization of optical, mechanical and chemical properties of diamond-like carbon thin film deposited on polymer substrate. Opt. Quantum Electron. 2018, 50, 1-17. [CrossRef]

23. Bito, K.; Hasebe, T.; Maegawa, S.; Maeda, T.; Matsumoto, T.; Suzuki, T.; Hotta, A. In vitro basic fibroblast growth factor (bFGF) delivery using an antithrombogenic 2-methacryloyloxyethyl phosphorylcholine (MPC) polymer coated with a micropatterned diamond-like carbon (DLC) film. J. Biomed. Mater. Res. Part A 2017, 105, 3384-3391. [CrossRef] [PubMed]

24. Khatir, S.; Hirose, A.; Xiao, C. Coating diamond-like carbon films on polymer substrates by inductively coupled plasma assisted sputtering. Surf. Coat. Technol. 2014, 253, 96-99. [CrossRef]

25. Zhao, Q.; Veldhuis, S.; Mathews, R.; Zhitomirsky, I. Influence of chemical structure of bile acid dispersants on electrophoretic deposition of poly (vinylidene fluoride) and composites. Colloids Surf. A Physicochem. Eng. Asp. 2021, 627, 127181. [CrossRef]

26. St. Hill, L.R.; Tran, H.-V.; Chinwangso, P.; Lee, H.J.; Marquez, M.D.; Craft, J.W.; Lee, T.R. Antifouling Studies of Unsymmetrical Oligo(ethylene glycol) Spiroalkanedithiol Self-Assembled Monolayers. Micro 2021, 1, 151-163. [CrossRef]

27. Kuganathan, N.; Ganeshalingam, S. Encapsulation and Adsorption of Halogens into Single-Walled Carbon Nanotubes. Micro 2021, 1, 140-150. [CrossRef]

28. Zhitomirsky, I.; Gal-Or, L. Formation of hollow fibers by electrophoretic deposition. Mater. Lett. 1999, 38, 10-17. [CrossRef]

29. Haveriku, S.; Meucci, M.; Badalassi, M.; Cardelli, C.; Ruggeri, G.; Pucci, A. Optimization of the Mechanical Properties of Polyolefin Composites Loaded with Mineral Fillers for Flame Retardant Cables. Micro 2021, 1, 102-119. [CrossRef]

30. Boane, J.L.N.; Centeno, P.; Mouquinho, A.; Alexandre, M.; Calmeiro, T.; Fortunato, E.; Martins, R.; Mendes, M.J.; Águas, H. Soft-Microstructured Transparent Electrodes for Photonic-Enhanced Flexible Solar Cells. Micro 2021, 1, 215-227. [CrossRef]

31. Wu, K.; Wang, Y.; Zhitomirsky, I. Electrophoretic deposition of TiO2 and composite TiO2-MnO2 films using benzoic acid and phenolic molecules as charging additives. J. Colloid Interface Sci. 2010, 352, 371-378. [CrossRef] [PubMed]

32. Mohanty, F.; Swain, S.K. Effect of graphene platelets on the thermal and conducting properties of poly (ethyl methacrylate). Adv. Polym. Technol. 2018, 37, 1316-1322. [CrossRef]

33. Abdelrazek, E. Influence of $\mathrm{FeCl} 3$ filler on the structure and physical properties of polyethyl-methacrylate films. Phys. B 2007, 400, 26-32. [CrossRef]

34. Ata, M.; Liu, Y.; Zhitomirsky, I. A review of new methods of surface chemical modification, dispersion and electrophoretic deposition of metal oxide particles. RSC Adv. 2014, 4, 22716-22732. [CrossRef]

35. Ata, M.S.; Poon, R.; Syed, A.M.; Milne, J.; Zhitomirsky, I. New developments in non-covalent surface modification, dispersion and electrophoretic deposition of carbon nanotubes. Carbon 2018, 130, 584-598. [CrossRef]

36. Baker, K.; Sikkema, R.; Liang, W.; Zhitomirsky, I. Multifunctional Properties of Commercial Bile Salts for Advanced Materials Engineering. Adv. Eng. Mater. 2021, 23, 2001261. [CrossRef]

37. Baker, K.; Sikkema, R.; Zhitomirsky, I. Application of bile acids for biomedical devices and sensors. Med. Devices Sens. 2020, 3, e10119. [CrossRef]

38. Miller-Chou, B.A.; Koenig, J.L. A review of polymer dissolution. Prog. Polym. Sci. 2003, 28, 1223-1270. [CrossRef]

39. Baker, K.; Zhitomirsky, I. A Versatile Strategy for the Fabrication of Poly (ethyl methacrylate) Composites. J. Compos. Sci. 2022, 6, 40. [CrossRef] 